\title{
Removal of Surfactant from Nanocomposites Films Based on Thermally Reduced Graphene Oxide and Natural Rubber
}

\author{
Hector Aguilar-Bolados ${ }^{1, *}$, Ahirton Contreras-Cid ${ }^{2}$, Andronico Neira-Carrillo ${ }^{3}$, \\ Miguel Lopez-Manchado ${ }^{4}\left(\mathbb{D}\right.$ and Mehrdad Yazdani-Pedram ${ }^{2}$ \\ 1 Facultad de Ciencias Físicas y Matemáticas, Universidad de Chile, Beauchef 850, Santiago, Chile \\ 2 Facultad de Ciencias Químicas y Farmacéuticas, Universidad de Chile, S. Livingstone 1007, Santiago, Chile; \\ ahirtoncontreras@gmail.com (A.C.-C.); myazdani@ciq.uchile.cl (M.Y.-P.) \\ 3 Facultad de Ciencias Veterinarias y Pecuarias, Universidad de Chile, Av. Santa Rosa 11735, Santiago, Chile; \\ aneira@uchile.cl \\ 4 Instituto de Ciencia y Tecnología de Polímeros, ICTP-CSIC, Juan de la Cierva, 3, 28006 Madrid, Spain; \\ lmanchado@ictp.csic.es \\ * Correspondence: haguilar@ciq.uchile.cl; Tel.: + 56-2-2978-2855
}

Received: 28 February 2019; Accepted: 25 March 2019; Published: 28 March 2019

\begin{abstract}
Electrically conducting elastomer composites based on natural rubber and reduced graphene oxide ( $\mathrm{rGO}$ ) is reported. These composites were prepared by a latex method and an easy washing process. The latex method consists of the mixing of an aqueous suspension of rGO, stabilized by sodium dodecyl sulfate and pre-vulcanized natural rubber, followed by solvent casting. The percolation threshold of composites was estimated at $1.54 \mathrm{wt} . \%$ of rGO. The washing process allowed elimination of the surfactant completely from nanocomposites. The absence of surfactant in nanocomposites was demonstrated by Raman spectroscopy and dynamo-mechanical analysis. The surfactant-free nanocomposites showed improved mechanical and electrical properties.
\end{abstract}

Keywords: thermally reduced graphene oxide; natural rubber latex; electrical properties; mechanical properties

\section{Introduction}

The advancement in the field of carbon polymorphs, such as carbon nanotubes and graphene, has significantly contributed to the development of new composites with different applications [1-6]. In the case of elastomers, electrically conducting rubber nanocomposites can be prepared by using carbon-based nanomaterials, such as graphene materials, as a filler [7]. These types of graphene materials can be prepared by diverse methods [8-10], however, the thermal reduction of graphite oxide (rGO) is considered as one of the easiest method [11,12]. Mastication, latex mixing and solution casting are the most used methods for the preparation of rubber nanocomposites. In the case of the latex method, this is carried out by using natural rubber latex and stable suspensions of graphene. There are some studies reported in the literature concerning the effect of graphene on the natural rubber latex properties [7,13-21]. In most of these studies, aqueous suspensions of graphene were incorporated in natural rubber latex followed by precipitation or drying the mixture, and a further vulcanization process using rollers or solvents over extended periods of time. Although these studies indicate the use of different strategies to improve graphene dispersion in the polymer matrix, few of them report how the properties of the resulting composites are affected by the presence of additives, such as surfactants. The aqueous suspensions of graphene are generally obtained by using surfactants, which are compounds of amphipathic character. Surfactants impart colloidal stability of hydrophobic 
materials, such as graphene, in water. The stabilization of graphene aqueous suspensions has been studied through the use of ionic and non-ionic surfactants. In the case of ionic surfactants, its use would achieve better suspension stabilization if the surfactant concentration was higher than or closer to the critical micelle concentration [22]. In the case of non-ionic surfactants, the concentration of graphene sheets coated with a surfactant is related linearly with a steric originated repulsive potential barrier. A high steric potential facilitates graphene dispersion in aqueous suspension [23]. Sodium dodecyl sulfate (SDS) is a low-cost commercially available anionic surfactant, which has been extensively studied for the preparation of stable water suspensions of graphene. These stable suspensions are proper for dispersing graphene in latexes of different polymers, especially rubber latex. This is due to the fact that the low viscosity of rubber latex allows an optimal dispersion, compared to mastication or roll milling methods. However, the addition of a surfactant alters the final composition and properties of the composites. As we previously reported, the use of SDS promotes the attainment of better colloidal stability to prepare $\mathrm{rGO}$ /natural rubber composites, while dodecyltrimethylamonium bromide (DTAB) promotes slight flocculation of natural rubber particles [18]. It is also possible to increase the electrical conductivity of natural rubber from $10^{-14} \mathrm{~S} / \mathrm{m}$ to $4.9 \times 10^{-2} \mathrm{~S} / \mathrm{m}$, when $4 \%$ rGO is used as the filler [20]. However, the elongation at the break was reduced drastically. Microdomains of surfactant in rubber composites could be the result of a high content of surfactant. These microdomains act as defect centers, producing the failure of the materials under mechanical stress.

The electrical percolation of carbon-based nanomaterials/rubber composites is explained by the percolation theory. This theory corresponds to a statistical physics model represented as the random connectivity of adjacent sites of hard-core circles, or cylinder or layer in an infinite periodic lattice [24-26]. The electrical conductivity measured in composites based on electrically conducting fillers and insulating polymer matrices is attributed to the formation of a three-dimensional interconnected network of the conductive phase. The critical filler content, where the composite becomes electrically conductive, is known as the percolation threshold $\left(\phi_{C}\right)$ [27]. The electron mobility of electrons is attributed to the tunneling between adjacent carbon particles improved by thermal fluctuations $[28,29]$. Hence, the presence of a surfactant surrounding the graphene in elastomer composites can affect the charge mobility, impeding the achievement of the optimal performance of electrical conductivity of the composite. In this respect, this work reports an easy treatment for the elimination of surfactant from the composites based on natural rubber and terminally reduced graphene oxide. The elimination of the surfactant from the rGO/natural rubber composite films should increase the electrical conductivity and promote the interaction between natural rubber and rGO, favoring the improvement of the mechanical properties.

\section{Experimental}

\subsection{Materials}

Double-centrifuged pre-vulcanized natural rubber latex (NR) with high ammonia content and with a total solid content of $56.87 \%$ (49.08\% of natural rubber), kindly supplied by TECNILATEX S.A. (Alcorcón, Madrid, Spain), was used. Reduced graphite oxide (rGO) was produced by a thermal reduction process of graphite oxide at $1000{ }^{\circ} \mathrm{C}$ under an argon atmosphere [7]. The graphite oxide was synthesized from natural graphite by the method of Brodie [30]. A thorough characterization of the material has been already reported [12]. The SDS supplied from Sigma-Aldrich was used as received.

\subsection{Preparation of $N R / r G O$ and $w-N R / r G O$ Nanocomposites}

The aqueous suspension of rGO was prepared by using a 1 wt.\% SDS solution, where the concentration of rGO was $0.3 \mathrm{wt}$.\%. The rGO was dispersed by sonication for $1 \mathrm{~h}$. Known volumes of the rGO suspensions were added to pre-vulcanized natural rubber latex to obtain nanocomposites containing between 1-4 wt.\% of rGO. Afterward, the samples were dried for $24 \mathrm{~h}$ at $70{ }^{\circ} \mathrm{C}$ and were designated as NR/rGO samples. The washing process of NR/rGO composites consisted in introducing the composite film in a $250 \mathrm{~mL}$ flask containing $200 \mathrm{~mL}$ of distilled water and was left stirring for $72 \mathrm{~h}$. 
Then, the film was removed, washed with distilled water and dried for $12 \mathrm{~h}$ at $70{ }^{\circ} \mathrm{C}$. These samples were termed $\mathrm{w}-\mathrm{NR} / \mathrm{rGO}$.

\subsection{Nanocomposite Characterization}

The nanocomposites were characterized by Raman spectroscopy, using a Renishaw Invia Raman microscope with a laser wavelength of $514.5 \mathrm{~nm}$ and a spectral resolution of $0.02 \mathrm{~cm}^{-1}$. Mechanical tests were carried out at room temperature and a pulling speed of $500 \mathrm{~mm} \cdot \mathrm{min}^{-1}$, using an Instron model 3366 dynamometer according to ASTM D 412 specifications. The results are the average of at least five measurements for each sample.

The degree of dispersion of the rGO layers and nanocomposite morphology were analyzed by transmission electron microscopy (TEM) using a Philips Tecnai 20 transmission electron microscope with an acceleration voltage of $200 \mathrm{kV}$. Samples of ultra-thin sections were prepared by cryoultramicrotomy at $-140{ }^{\circ} \mathrm{C}$, using a Leica EM UC6 cryoultramicrotome ((Leica, Vienna, Austria).

The dynamic mechanical analysis was carried out using a Mettler Toledo 861e DMA. The tension mode was $1 \mathrm{~Hz}$ and the temperature range was between -100 and $0{ }^{\circ} \mathrm{C}$, with a heating rate of $2{ }^{\circ} \mathrm{C} \cdot \mathrm{min}^{-1}$. The experimental error was less than $5 \%$. The electrical conductivity of the nanocomposites was measured on a high-resolution Alpha-Novocontrol dielectric spectrometer. The films were placed in the dielectric cell between two parallel gold electrodes. The conductivity measurement was given directly by the analyzer.

\section{Results and Discussion}

\subsection{Raman Spectroscopy}

The Raman spectra of natural rubber (NR) and washed NR (w-NR) are shown in Figure 1. An intense band at $1666 \mathrm{~cm}^{-1}$ was observed, which corresponded to the $C=C$ stretching. Other characteristic bands of natural rubber were seen, such as $1444 \mathrm{~cm}^{-1}, 1368 \mathrm{~cm}^{-1}$ and $993 \mathrm{~cm}^{-1}$, which corresponded to $\mathrm{CH}_{2}$ deformation, $\mathrm{CH}_{3}$ asymmetric deformation and $\mathrm{C}_{-} \mathrm{CH}_{2}$ stretching, respectively [31]. No significant changes were observed as a consequence of the washing of the NR film with water. This indicated that, despite the washing of the film, the natural rubber did not present a significant change in its composition. Figure 2 shows the Raman spectra of the natural rubber/rGO composites and washed natural rubber/rGO composite, where the characteristic D and G bands of the graphene materials were observed. In the case of washed composites, a Raman red-shift for the band associated with $C=C$ stretching of the NR was observed. Simultaneously, the G and D bands presented a Raman blue-shift. These facts suggested that the elimination of the surfactant was successful, favoring interactions between the natural rubber backbone and the reduced graphene oxide.

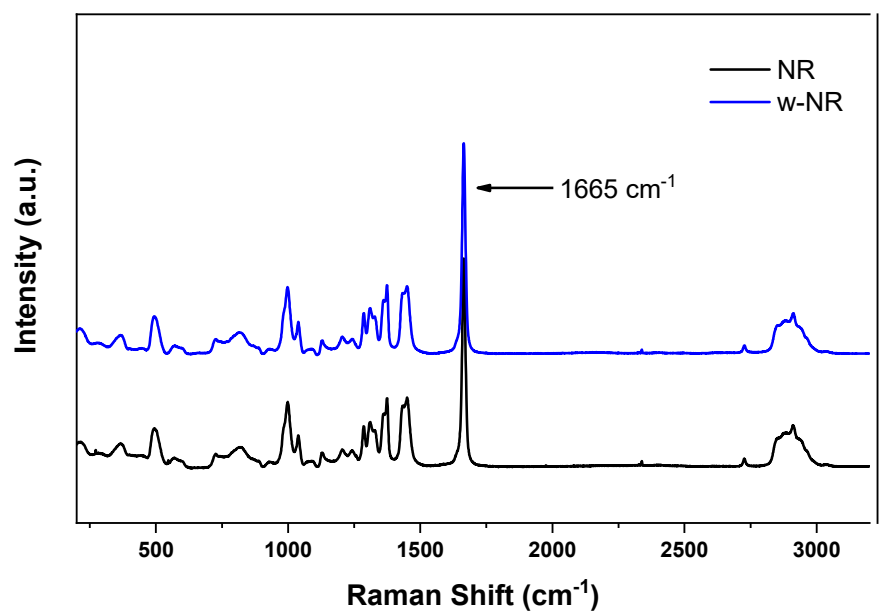

Figure 1. Raman spectra of natural rubber (NR) and washed (w)-NR. 


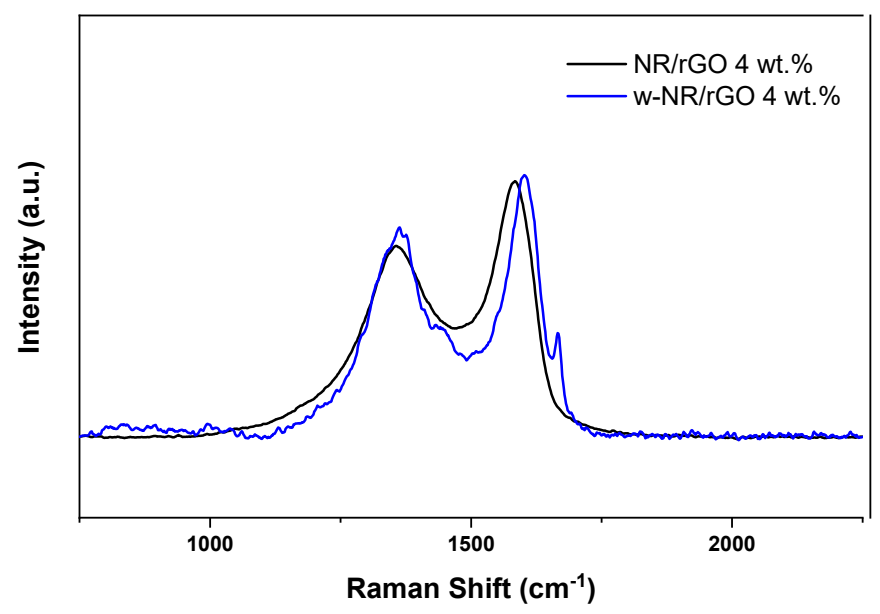

Figure 2. Raman spectra of natural rubber/reduced graphene oxide (NR/rGO) $4.0 \mathrm{wt} \%$ and w-NR/rGO 4.0 wt.\%.

\subsection{Electrical Conductivity of $N R / r G O$ Nanocomposites}

The electrical conductivity measured at $1 \mathrm{~Hz}$, as a function of the rGO content, is shown in Figure 3 . It was observed that the electrical conductivity of NR is $2.66 \times 10^{-10} \mathrm{~S} / \mathrm{m}$, which is characteristic of electrically insulating materials. The electrical conductivity increased up to $9.06 \times 10^{-5} \mathrm{~S} / \mathrm{m}$ with $4 \mathrm{wt} . \%$ of rGO content, as a consequence of the addition of reduced graphene oxide to the natural rubber. The percolation threshold of rGO was around $2.50 \mathrm{wt} . \%$. In the case of the washed nanocomposites, it was observed that the electrical conductivity of each composite partially increased. The electrical conductivity of composites with $4 \mathrm{wt} . \%$ achieved a value of $6.16 \times 10^{-5} \mathrm{~S} / \mathrm{m}$ and the percolation threshold decreased, reaching a value of $1.54 \mathrm{wt} . \%$. This increase could be attributed to the fact that small SDS molecules occupy the free volume, inhibiting the tunneling of an electron between the reduced graphene oxide layers. As a consequence of the elimination of SDS, an increase of the electrical conductivity was achieved. In this respect, the effect of small molecules-such as the solvent on the electrical properties of carbon-based elastomer composites-was reported by Pavlovsky and Siegmann [32], who demonstrated that the reversible swelling of carbon-based composites allows the occurrence of the breakdown and reconstruction of the filler conducting network. The electrical conductivity observed in $\mathrm{w}-\mathrm{NR} / \mathrm{rGO}$ could be attributed mainly by the occurrence of tunneling between the adjacent rGO layers, since there is a predominance of electronic conductivity. It is interesting to note that in the literature, there are other materials, which present similar orders of electrical conductivity, such as those nanocomposites based on polymer electrolytes. However, the electrical conductivity of these types of composites is attributed to ionic conductivity $[33,34]$.

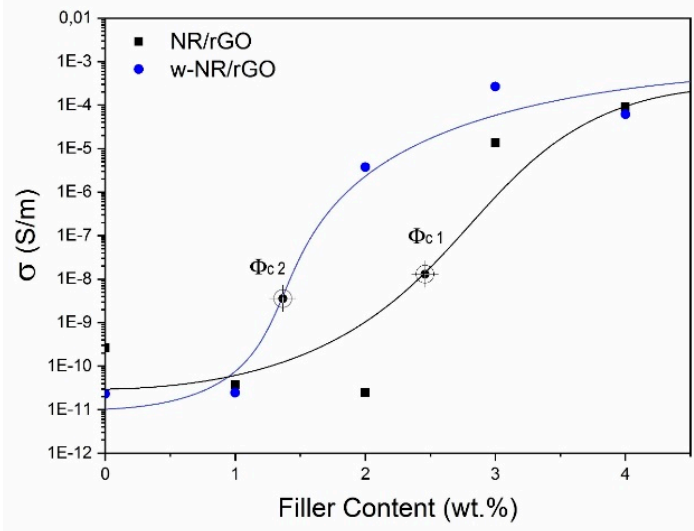

Figure 3. Electrical conductivity of $\mathrm{NR} / \mathrm{rGO}$ and $\mathrm{w}-\mathrm{NR} / \mathrm{rGO}$ composites as a function of the rGO content. 


\subsection{Mechanical Properties of NR/Reduced Graphene Oxide Composites}

Table 1 presents the modulus at $100 \%$ and $300 \%$ of elongation, the ultimate tensile strength and elongation at break of the NR and nanocomposites. As expected, the addition of rGO to NR promoted the increase of stiffness of the resulting nanocomposites. This could be attributed to the fact that the filler partially occupies the free volume fraction, inhibiting the free rotation of polymer chains. In addition, the increase of the filler ( $\mathrm{rGO}$ ) content produced a decrease of the elongation at break of the composite. This fact was related to the presence of filler, which induced defects in the composites. An interesting fact was observed as a consequence of the washing process. The $\mathrm{w}-\mathrm{NR} / \mathrm{rGO}$ samples with contents of $1 \mathrm{wt} . \%, 2 \mathrm{wt} . \%$ and $3 \mathrm{wt} . \%$ of rGO presented a lower E100 modulus. This fact could be related to the elimination of the surfactant from the nanocomposites as a result of the washing process. In addition, washed composites presented a tendency to have higher ultimate tensile strength than unwashed composites. This could be attributed to the fact that the elimination of the surfactant molecules allowed the natural rubber chains to be in closer contact with the filler, which improved their interactions. Likewise, the elimination of the surfactant could reduce the surfactant microdomains, which can act as failure centers in composites films.

Table 1. Modulus at $100 \%$ and $300 \%$ of elongation, ultimate tensile strength and elongation at break of $\mathrm{NR} / \mathrm{rGO}$ and $\mathrm{w}-\mathrm{NR} / \mathrm{rGO}$ composites.

\begin{tabular}{ccccc}
\hline Sample & $\begin{array}{c}\text { Modulus E100 } \\
\text { (MPa) }\end{array}$ & $\begin{array}{c}\text { Modulus E300 } \\
\text { (MPa) }\end{array}$ & $\begin{array}{c}\text { Ultimate Tensile } \\
\text { Strength (MPa) }\end{array}$ & $\begin{array}{c}\text { Elongation at } \\
\text { Break (\%) }\end{array}$ \\
\hline NR & 0.80 & 1.53 & 19.5 & 754 \\
NR/rGO 1 wt.\% & 1.07 & 2.74 & 25.2 & 674 \\
NR/rGO 2 wt.\% & 1.52 & 4.37 & 22.1 & 596 \\
NR/rGO 3 wt.\% & 2.14 & 6.07 & 24.1 & 602 \\
NR/rGO 4 wt.\% & 1.93 & 5.49 & 15.9 & 495 \\
w-NR/rGO 1 wt.\% & 0.96 & 2.44 & 24.9 & 691 \\
w-NR/rGO 2 wt. $\%$ & 1.52 & 4.70 & 24.8 & 620 \\
w-NR/rGO 3 wt. $\%$ & 1.95 & 6.17 & 19.4 & 526 \\
w-NR/rGO 4 wt. $\%$ & 2.48 & 7.44 & 19.3 & 423 \\
\hline
\end{tabular}

\subsection{Morphology of NR/Reduced Graphene Oxide Composites}

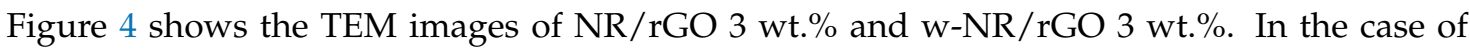
$\mathrm{NR} / \mathrm{rGO}$, it was observed that the layers of reduced graphene oxide were dispersed in an elastomeric matrix. However, there were zones were the rGO layers appeared partially stacked and the formation of a filler network was observed. Previously, it has been reported that in natural rubber composites filled with graphene prepared by using the latex method, the graphene layers tended to occupy the interstices between the NR particles [7]. This indicates that although the surfactant enhances the stability of graphene in an aqueous suspension, the dispersion of the reduced graphene oxide layers will be affected by the characteristic of the NR particles and their stability. As a result of the washing process, the rGO layers appeared more dispersed in the elastomer matrix. This suggested that a higher interaction between the rGO layers and polymer matrix can take place as the consequence of the elimination of the surfactant by using the washing process. 


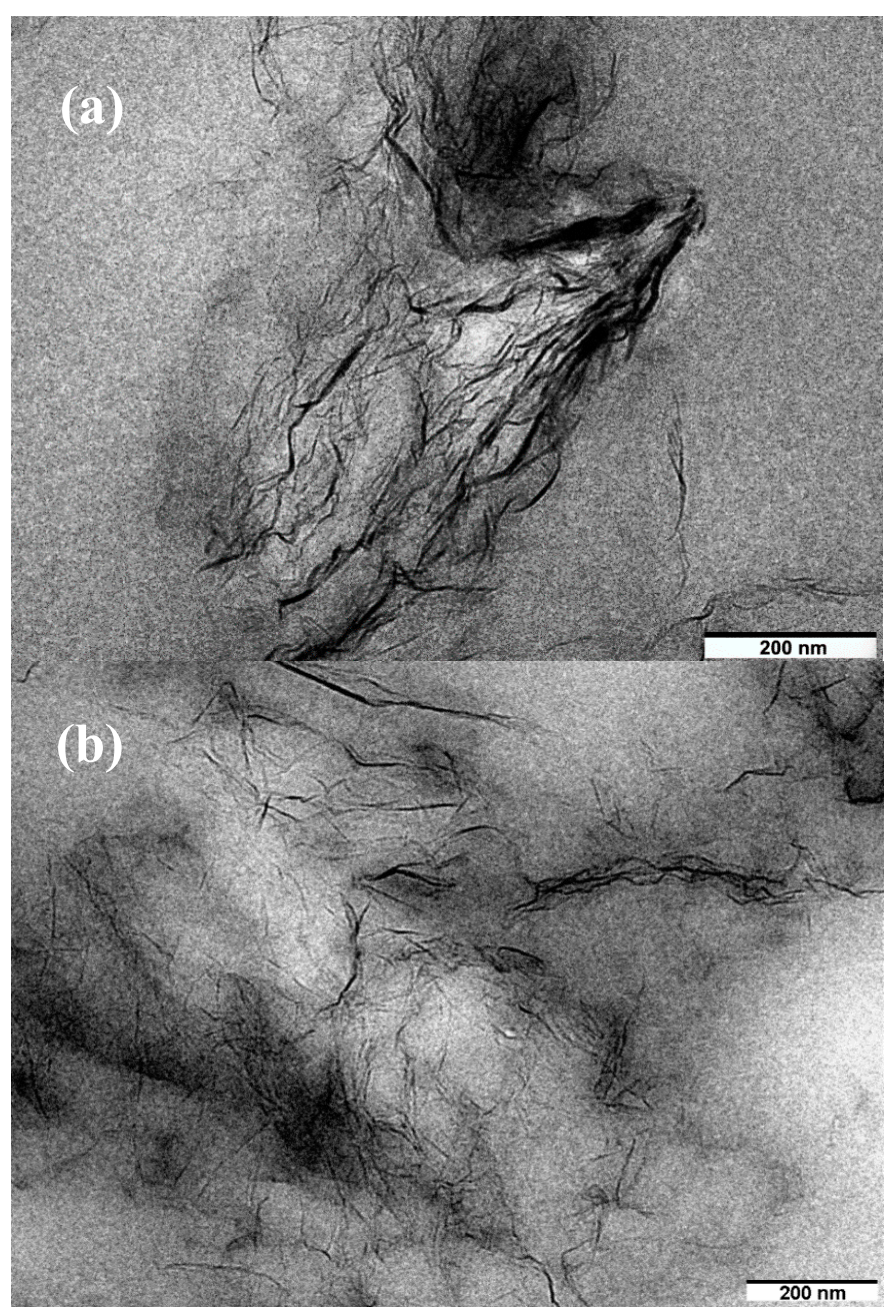

Figure 4. Transmission electron microscopy of NR/rGO 3 wt. $\%$ (a) and w-NR/rGO 3wt.\% (b).

\subsection{Dynamo-Mechanical of NR/Reduced Graphene Oxide Composites}

A dynamo-mechanical analysis provides information on the viscoelastic properties of materials, where the elastic portion is represented by the storage modulus and the viscous portion is represented by the loss modulus. Figures 5 and 6 present the storage modulus and loss modulus, respectively, of NR, NR / rGO $4 \mathrm{wt} . \%$ and $\mathrm{w}-\mathrm{NR} / \mathrm{rGO} 4 \mathrm{wt} . \%$ in the temperature range of $-80{ }^{\circ} \mathrm{C}$ to $-30{ }^{\circ} \mathrm{C}$. It was observed that the storage modulus of all samples showed a fall around $-60^{\circ} \mathrm{C}$, which corresponded to the glass transition temperature of NR [7]. The addition, the SDS-dispersed rGO produced a storage modulus increase of around $-50{ }^{\circ} \mathrm{C}$, which could indicate that the SDS molecules affect the cooperative movement of the natural rubber backbone. This was also observed in the loss modulus of $\mathrm{NR} / \mathrm{rGO}$ $4 \mathrm{wt} . \%$, where a bimodal peak was observed. The presence of SDS did not significantly alter the glass transition temperature (Tg) of NR, but its presence produced a composite that could present partial heterogeneity. Instead, the $\mathrm{w}-\mathrm{NR} / \mathrm{rGO} 4 \mathrm{wt} . \%$ presented storage and the loss modulus shifted to a higher temperature. This suggested that the washing process eliminated the surfactant from the nanocomposite, which promoted the interaction between $\mathrm{rGO}$ and natural rubber. 


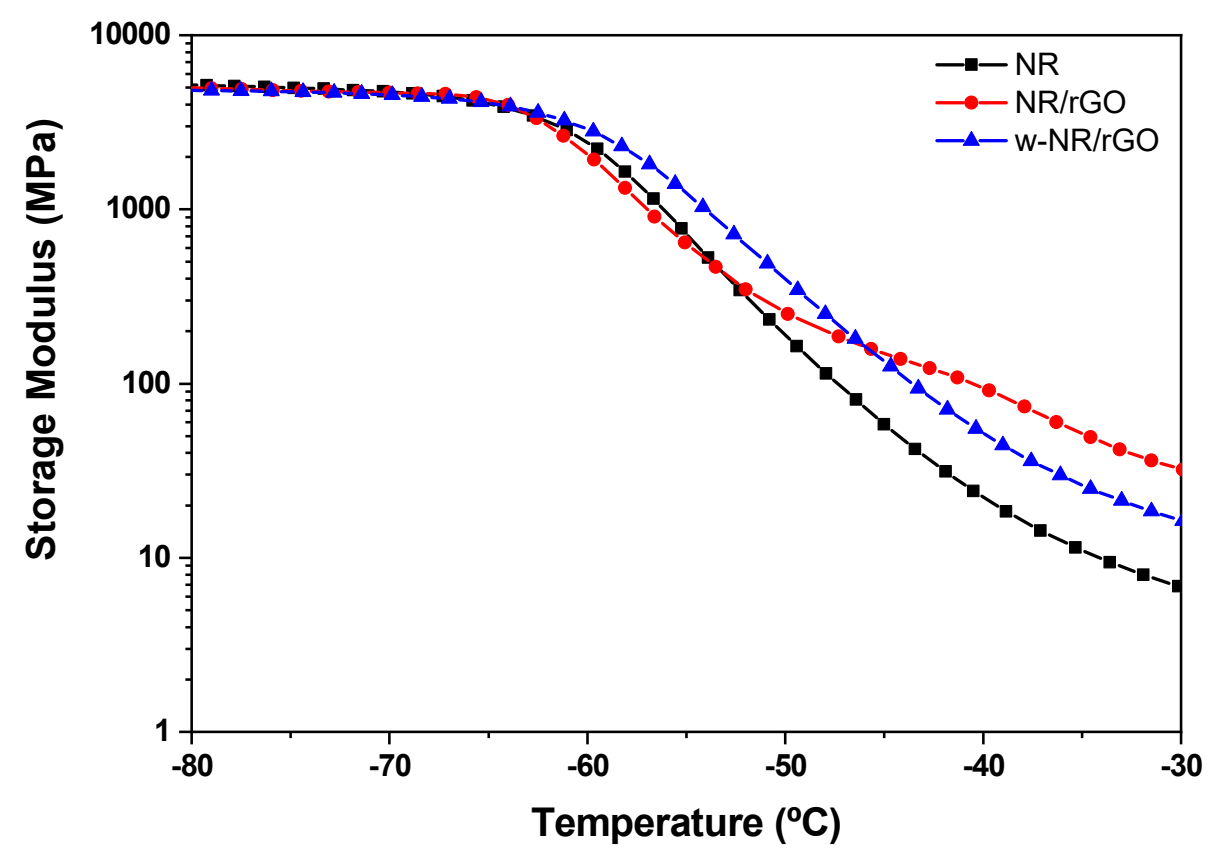

Figure 5. Storage modulus of NR, NR/rGO $4.0 \mathrm{wt} . \%$ and $\mathrm{w}-\mathrm{NR} / \mathrm{rGO} 4.0 \mathrm{wt} . \%$.

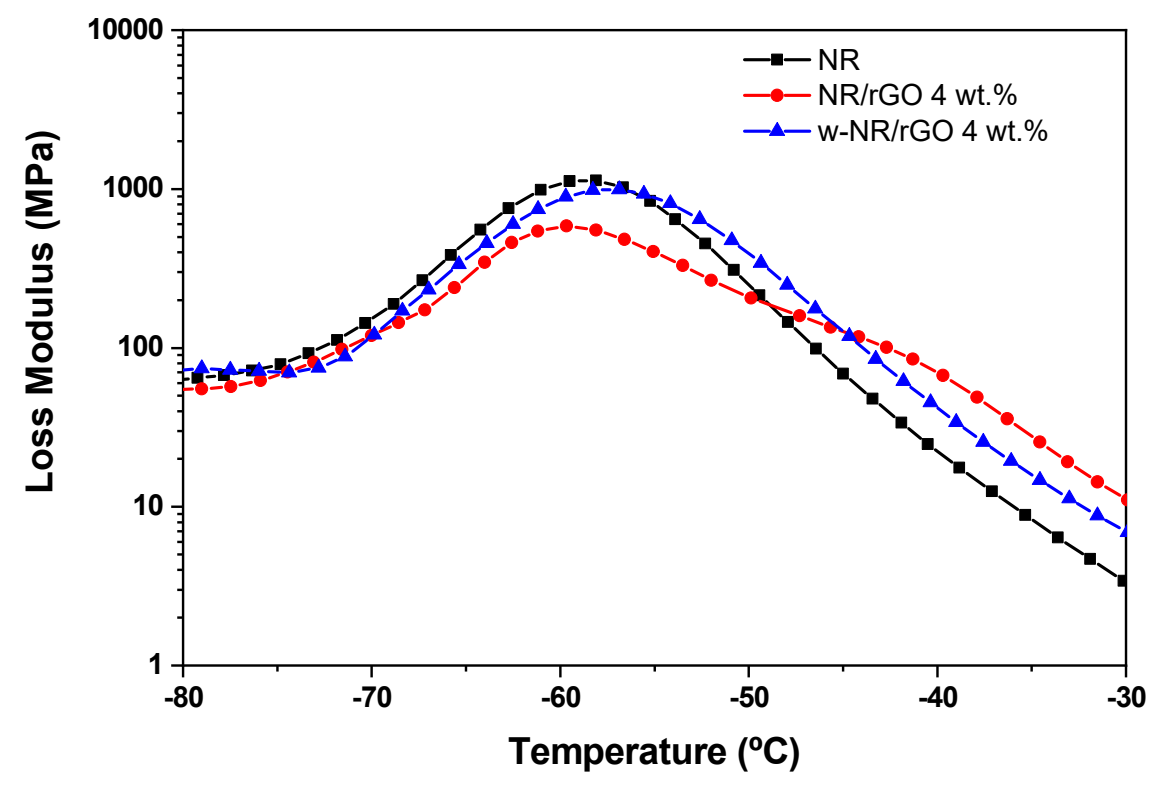

Figure 6. Loss modulus of NR, NR/rGO $4.0 \mathrm{wt} . \%$ and w-NR/rGO $4.0 \mathrm{wt} . \%$.

\section{Conclusions}

Successful elimination of SDS surfactant from elastomer nanocomposites, based on NR/rGO, was demonstrated by using Raman spectroscopy. The elimination of this surfactant resulted in an improvement of the mechanical and electrical properties of the nanocomposites. In this respect, it was demonstrated that the percolation threshold decreased from $2.6 \mathrm{wt} . \%$ to $1.65 \mathrm{wt} . \%$ and the ultimate tensile strength slightly increased by the washing process. An important outcome of this research, as ascertained using dynamo-mechanical analysis, is that the presence of a surfactant impedes the free rotation of the natural rubber backbone.

Author Contributions: Conceptualization, H.A.-B. and M.L.-M.; Methodology, H.A.-B.; Investigation, H.A.-B. and M.Y.-P.; Writing-Original Draft Preparation, H.A.-B. and A.C.-C.; Writing-Review \& Editing, M.Y.-P. and A.N.-C.; Project Administration, M.L.-M. 
Funding: Miguel Lopez-Manchado thanks the support from MINECO (grant number MAT2016-81138-R).

Conflicts of Interest: The authors declare no conflict of interest.

\section{References}

1. Iijima, S. Helical microtubules of graphitic carbon. Nature 1991, 354, 56-58. [CrossRef]

2. Novoselov, K.S.; Geim, A.K.; Morozov, S.V.; Jiang, D.; Zhang, Y.; Dubonos, S.V.; Grigorieva, I.V.; Firsov, A.A. Electric Field Effect in Atomically Thin Carbon Films. Science 2004, 306, 666-669. [CrossRef] [PubMed]

3. Das, A.; Stöckelhuber, K.W.; Jurk, R.; Saphiannikova, M.; Fritzsche, J.; Lorenz, H.; Klüppel, M.; Heinrich, G. Modified and unmodified multiwalled carbon nanotubes in high performance solution-styrene-butadiene and butadiene rubber blends. Polymer 2008, 49, 5276-5283. [CrossRef]

4. Lorenz, H.; Fritzsche, J.; Das, A.; Stöckelhuber, K.W.; Jurk, R.; Heinrich, G.; Klüppel, M. Advanced elastomer nano-composites based on CNT-hybrid filler systems. Compos. Sci. Technol. 2009, 69, 2135-2143. [CrossRef]

5. Rooj, S.; Das, A.; Thakur, V.; Mahaling, R.N.; Bhowmick, A.K.; Heinrich, G. Preparation and properties of natural nanocomposites based on natural rubber and naturally occurring halloysite nanotubes. Mater. Des. 2010, 31, 2151-2156. [CrossRef]

6. Garlof, S.; Fukuda, T.; Mecklenburg, M.; Smazna, D.; Mishra, Y.K.; Adelung, R.; Schulte, K.; Fiedler, B. Electro-mechanical piezoresistive properties of three dimensionally interconnected carbon aerogel (Aerographite)-epoxy composites. Compos. Sci. Technol. 2016, 134, 226-233. [CrossRef]

7. Aguilar-Bolados, H.; Brasero, J.; Lopez-Manchado, M.A.; Yazdani-Pedram, M. High performance natural rubber/thermally reduced graphite oxide nanocomposites by latex technology. Compos. Part B Eng. 2014, 67, 449-454. [CrossRef]

8. Aguilar-Bolados, H.; Contreras-Cid, A.; Yazdani-Pedram, M.; Acosta-Villavicencio, G.; Flores, M.; Fuentealba, P.; Neira-Carrillo, A.; Verdejo, R.; López-Manchado, M.A. Synthesis of fluorinated graphene oxide by using an easy one-pot deoxyfluorination reaction. J. Colloid Interface Sci. 2018, 524, 219-226. [CrossRef] [PubMed]

9. Aguilar-Bolados, H.; Vargas-Astudillo, D.; Yazdani-Pedram, M.; Acosta-Villavicencio, G.; Fuentealba, P.; Contreras-Cid, A.; Verdejo, R.; López-Manchado, M.A. Facile and Scalable One-Step Method for Amination of Graphene Using Leuckart Reaction. Chem. Mater. 2017, 29, 6698-6705. [CrossRef]

10. Stobinski, L.; Lesiak, B.; Malolepszy, A.; Mazurkiewicz, M.; Mierzwa, B.; Zemek, J.; Jiricek, P.; Bieloshapka, I. Graphene oxide and reduced graphene oxide studied by the XRD, TEM and electron spectroscopy methods. J. Electron Spectrosc. Relat. Phenom. 2014, 195 (Suppl. C), 145-154. [CrossRef]

11. Botas, C.; Álvarez, P.; Blanco, C.; Santamaría, R.; Granda, M.; Gutiérrez, M.D.; Rodríguez-Reinoso, F.; Menéndez, R. Critical temperatures in the synthesis of graphene-like materials by thermal exfoliation-reduction of graphite oxide. Carbon 2013, 52, 476-485. [CrossRef]

12. Botas, C.; Álvarez, P.; Blanco, P.; Granda, M.; Blanco, C.; Santamaría, R.; Romasanta, L.J.; Verdejo, R.; López-Manchado, M.A.; Menéndez, R. Graphene materials with different structures prepared from the same graphite by the Hummers and Brodie methods. Carbon 2013, 65, 156-164. [CrossRef]

13. Hernández, M.; Bernal, M.; Verdejo, R.; Ezquerra, T.; López-Manchado, M. Overall performance of natural rubber/graphene nanocomposites. Compos. Sci. Technol. 2012, 73, 40-46. [CrossRef]

14. Li, C.; Feng, C.; Peng, Z.; Gong, W.; Kong, L. Ammonium-assisted green fabrication of graphene/natural rubber latex composite. Polym. Compos. 2013, 34, 88-95. [CrossRef]

15. Wu, J.; Xing, W.; Huang, G.; Li, H.; Tang, M.; Wu, S.; Liu, Y. Vulcanization kinetics of graphene/natural rubber nanocomposites. Polymer 2013, 54, 3314-3323. [CrossRef]

16. Xing, W.; Wu, J.; Huang, G.; Li, H.; Tang, M.; Fu, X. Enhanced mechanical properties of graphene/natural rubber nanocomposites at low content. Polym. Int. 2014, 63, 1674-1681. [CrossRef]

17. Matos, C.; Galembeck, F.; Zarbin, A. Multifunctional and environmentally friendly nanocomposites between natural rubber and graphene or graphene oxide. Carbon 2014, 78, 469-479. [CrossRef]

18. Aguilar-Bolados, H.; Yazdani-Pedram, M.; Brasero, J.; Lopez-Manchado, M. Influence of the Surfactant Nature on the Occurrence of Self-Assembly between Rubber Particles and Thermally Reduced Graphite Oxide during the Preparation of Natural Rubber Nanocomposites. J. Nanomater. 2015, 16, 311. [CrossRef]

19. Aguilar-Bolados, H.; Lopez-Manchado, M.; Brasero, J.; Avilés, F.; Yazdani-Pedram, M. Effect of the morphology of thermally reduced graphite oxide on the mechanical and electrical properties of natural rubber nanocomposites. Compos. Part B Eng. 2016, 87, 350-356. [CrossRef] 
20. Aguilar-Bolados, H.; Yazdani-Pedram, M.; Contreras-Cid, A.; López-Manchado, M.; May-Pat, A.; Avilés, A. Influence of the morphology of carbon nanostructures on the piezoresistivity of hybrid natural rubber nanocomposites. Compos. Part B Eng. 2017, 109, 147-154. [CrossRef]

21. Kang, H.; Tang, Y.; Yao, L.; Yang, F.; Fang, Q.; Hui, D. Fabrication of graphene/natural rubber nanocomposites with high dynamic properties through convenient mechanical mixing. Compos. Part B Eng. 2017, 112, 1-7. [CrossRef]

22. Bystrzejewski, M.; Huczko, A.; Lange, H.; Gemming, T.; Büchner, B.; Rümmeli, M.H. Dispersion and diameter separation of multi-wall carbon nanotubes in aqueous solutions. J. Colloid Interface Sci. 2010, 345, 138-142. [CrossRef] [PubMed]

23. Smith, R.J.; Lotya, M.; Coleman, J.N. The importance of repulsive potential barriers for the dispersion of graphene using surfactants. New J. Phys. 2010, 12, 125008. [CrossRef]

24. Scher, H.; Zallen, R. Critical Density in Percolation Processes. J. Chem. Phys. 1970, 53, 3759-3761. [CrossRef]

25. Liang, G.D.; Tjong, S.C. Electrical properties of percolative polystyrene/carbon nanofiber composites. IEEE Trans. Dielectr. Electr. Insul. 2008, 15, 214-220. [CrossRef]

26. Lu, W.; Lin, H.; Wu, D.; Chen, G. Unsaturated polyester resin/graphite nanosheet conducting composites with a low percolation threshold. Polymer 2006, 47, 4440-4444. [CrossRef]

27. Mamunya, E.P.; Davidenko, V.V.; Lebedev, E.V. Percolation conductivity of polymer composites filled with dispersed conductive filler. Polym. Compos. 1995, 16, 319-324. [CrossRef]

28. Li, C.; Thostenson, E.T.; Chou, T.-W. Dominant role of tunneling resistance in the electrical conductivity of carbon nanotube-based composites. Appl. Phys. Lett. 2007, 91, 223114. [CrossRef]

29. He, L.; Tjong, S.C. Low percolation threshold of graphene/polymer composites prepared by solvothermal reduction of graphene oxide in the polymer solution. Nanoscale Res. Lett. 2013, 8, 132. [CrossRef] [PubMed]

30. Brodie, B.C. On the Atomic Weight of Graphite. Philos. Trans. R. Soc. Lond. 1859, 149, $249-259$.

31. Prasertsri, S.; Lagarde, F.; Rattanasom, N.; Sirisinha, C.; Daniel, P. Raman spectroscopy and thermal analysis of gum and silica-filled NR/SBR blends prepared from latex system. Polym. Test. 2013, 32, 852-861. [CrossRef]

32. Pavlovsky, S.; Siegmann, A. Chemical sensing materials II: Electrically conductive peroxide crosslinked SEBS copolymers systems. J. Appl. Polym. Sci. 2009, 114, 1390-1396. [CrossRef]

33. Verma, M.L.; Minakshi, M.; Singh, N.K. Structural and Electrochemical Properties of Nanocomposite Polymer Electrolyte for Electrochemical Devices. Ind. Eng. Chem. Res. 2014, 53, 14993-15001. [CrossRef]

34. Verma, M.L.; Minakshi, M.; Singh, N.K. Synthesis and Characterization of Solid Polymer Electrolyte based on Activated Carbon for Solid State Capacitor. Electrochim. Acta 2014, 137, 497-503. [CrossRef] 